\title{
A Study for Optimum Survey Method of Underwater Structure Using the Dual Sonar Sensor
}

\author{
Youngseok Kim, Heungsu Lee, Chul Park, and Sangsik Choi \\ Daum Engineering Co., Ltd., Seongnam-si, Republic of Korea \\ Correspondence should be addressed to Youngseok Kim; youngseok21c@hanmail.net
}

Received 9 December 2016; Revised 14 February 2017; Accepted 8 March 2017; Published 22 May 2017

Academic Editor: Yinan Zhang

Copyright (C) 2017 Youngseok Kim et al. This is an open access article distributed under the Creative Commons Attribution License, which permits unrestricted use, distribution, and reproduction in any medium, provided the original work is properly cited.

\begin{abstract}
We have developed dual sonar equipment and an improved operating method for improving resolution in order to solve the problems of limitations of the optical equipment and the application method of SSS (side scan sonar) in the investigation of damage of underwater structures. We analyzed the influence factors of the resolution of sonar data through the comparison of resolution and data quality in indoor test. Also we confirmed the problems about the overlapping area of the dual sonar. Depth and distance were analyzed as major influencing factors for survey angle. Specimens were scanned while adjusting distance and towfish angle according to depth change in order to verify applicability of the developed dual sonar in the field experiment. Optimal resolution was found to be $3 \mathrm{~cm}$ in specimen spacing, and 20 sample data items were extracted. We developed the regression model based on the multiple regression analysis and developed the RealDualSONAR-DAQ tool, the dual sonar optimum operating method program based on proposed correlation equations. We can use the developed tools to get the value of the major influencing factors for dual sonar operation and obtain high quality sonar data to analyze damage of underwater structures.
\end{abstract}

\section{Introduction}

In South Korea, after the collapse of the Seongsu Bridge (1994) [1], the "Special Act on Safety Management of Public Facilities" was enacted and promulgated, and the routine inspections, the detailed inspections, and the precision safety diagnosis are carried out regularly according to condition of facilities. However, the possibility of disasters in bridges and underwater structures is increasing due to the deterioration of facilities and the increase in the frequency of rainfall due to abnormal weather and scouring phenomenon around the underwater structure, scaling and exfoliation of structure's surface, and damage and cracking due to the impact of floating materials acceleration. And there is the high possibility that the structure will collapse due to the overturn or breakage of the structure in severe cases [2].

In general, conventional methods have been used such as underwater inspections by diving personnel and depth surveying. This method uses optical equipment, so if the turbidity is not good, it is difficult to identify the damage $[3,4]$. In addition, divers have safety problems due to environmental influences such as flow velocity and tidal current and securing visibility. The research to apply "Remote-Operated-Vehicle (ROV)" or "SOund-NAvigation and Ranging (sonar)" as a solution to problems is actively underway [5]. However, since ROV is mainly used with the optical equipment, it is difficult to apply it in the Korean sea where the turbidity is high and the tide is strong [6]. Also, sonar is towing equipment and is mainly used for surveying the river/sea bed. It is not suitable for direct application to investigation of underwater structures because angle adjustment is impossible. Therefore, in this study, a development of effective equipment to investigate damage of underwater structures using sonar and an operating method to improve the resolution of sonar data were studied.

\section{Applicability Analysis of Sonar Sensor}

2.1. Theoretical Background of Sonar. Sonar is a device that detects azimuth and distance of a target by a sound wave. Since electromagnetic wave is transmitted faster and farther than sound wave in the air, radar (Radio Detecting and Ranging) is capable of detecting ground and marine object, and corresponding equipment for underwater use is sonar. 


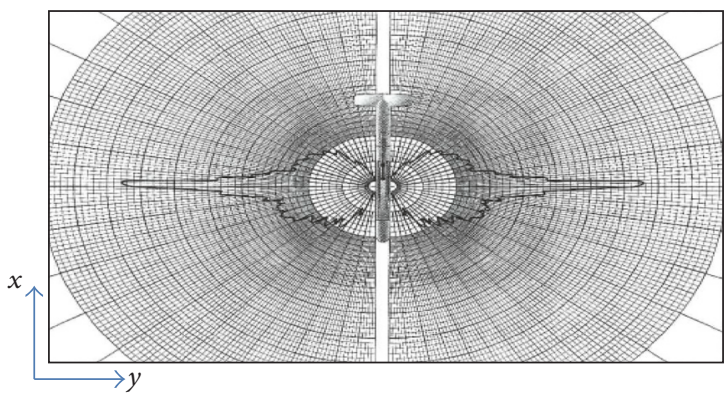

(a) Planar irradiation form of sonar beam

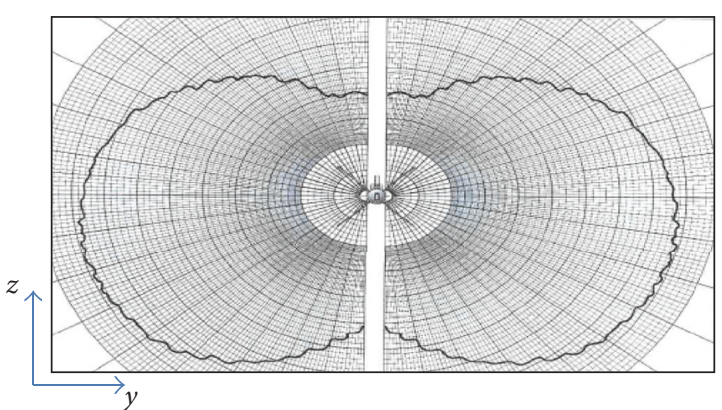

(b) Front irradiation form of sonar beam

FIGURE 1: Irradiation form of sonar beam.

TABLE 1: The evaluation standard of resolution and data.

\begin{tabular}{|c|c|c|}
\hline Class & Resolution & Data rating \\
\hline A & $\begin{array}{l}\text { Structural evaluation possible } \\
\text { (Verification tile spacing over } 90 \% \text { of total area) }\end{array}$ & $\begin{array}{l}\text { Excellent data accuracy } \\
\text { (Scanning wall over } 4 \mathrm{~m} \text { ) }\end{array}$ \\
\hline B & $\begin{array}{l}\text { Possible to distinguish overall } \\
\text { (Verification tile spacing over } 70 \% \text { of total area) }\end{array}$ & $\begin{array}{l}\text { Possible to distinguish the overall data } \\
\text { (Scanning wall over } 3 \mathrm{~m} \text { ) }\end{array}$ \\
\hline $\mathrm{C}$ & $\begin{array}{l}\text { Can be identified for some area } \\
\text { (Verification tile spacing over } 50 \% \text { of total area) }\end{array}$ & $\begin{array}{l}\text { Data can be separated for some area } \\
\text { (Scanning wall over } 2 \mathrm{~m})\end{array}$ \\
\hline $\mathrm{D}$ & $\begin{array}{l}\text { Not identifiable overall } \\
\text { (Verification tile spacing over } 30 \% \text { of total area) }\end{array}$ & $\begin{array}{l}\text { Poor data accuracy overall } \\
\text { (Scanning wall over } 1 \mathrm{~m})\end{array}$ \\
\hline
\end{tabular}

The sound wave applied to sonar has a pressure wave of about $1,500 \mathrm{~m} / \mathrm{sec}$ and has the property of transmitting well in water. Therefore, so far, various types of sonar have been developed and operated according to the purpose and use, as the only means of detecting targets in the water in an active or passive way $[7,8]$. Side scan sonar (SSS) system is an underwater ultrasonic system that scans both sides. As a towfish (towed underwater) is towed by the traction signal cable, the towfish sends and receives ultrasound underwater from transducers on both sides. It is a system that transmits a signal through a traction signal cable and restores the shape into a twodimensional image using a signal and an image processing apparatus [9].

2.2. Resolution Factor Analysis of Sonar Data. If you want to focus on the subject when you take pictures using a camera, you need to adjust the lens, aperture, shutter speed, sensitivity, and so forth to get a clear picture. An autofocusing function has been developed that automatically captures the subject's focus as it progresses from a manual camera to a DSLR. Side scan sonar (SSS) also has factors that affect the quality of data [10]. As shown in Figure 1, $x$ is an axial direction of the towfish, $y$ is a perpendicular direction, and $z$ is a vertical direction. Since the main beam and the auxiliary beam do not radiate in a regular shape, there may be a difference in resolution depending on the contact surface of the beam. Therefore, we tried to grasp influence factors for obtaining high resolution data [7].

When operating underwater imaging equipment, the resolution of data collected can vary depending on angle of the towfish and distance from the structure [8]. Therefore, we carried out various verification experiments to obtain high quality data by operating the underwater image acquisition equipment appropriately according to the situation. Through indoor experiments, we confirmed the resolution change of the data collected at the same depth $(5 \mathrm{~m})$ according to angle of the towfish and distance from the structure as shown in Figures 2(a) and 2(b).

As shown in Table 1, the resolution was evaluated according to the verification of tile spacing in total area, and the data grade was evaluated with range scanned in $5 \mathrm{~m}$ wall. As shown in (c) to (f) of Figure 2, the resolution and the data quality were evaluated at different distances and angles. Here, the yellow line in sonar data is tile joint in the wall and the highlight in sonar data depends on sound intensity and resolution. The resolution changes according to distance and angle are summarized as the graph in Figure 3.

As shown in the above results, the resolution of sonar data is influenced by distance from the structure and angle of the towfish. The shape of the beams emitted from sonar is not linear and the intensity of sound waves is different. Therefore, it is considered that the resolution depends on angle and distance.

2.3. Overlay Analysis. The existing SSS is basically equipped with transducers on left and right sides of towfish for the purposes of survey of the seabed. This equipment needs to be improved in order to apply this equipment to underwater structures' surveys. In general, the underwater survey is carried out to assess the damage of structures and bed topography and to judge them comprehensively. Therefore, since the existing SSS is difficult to simultaneously investigate riverbed and underwater structures and work efficiency is low, two towfishes are used to investigate river and underwater 


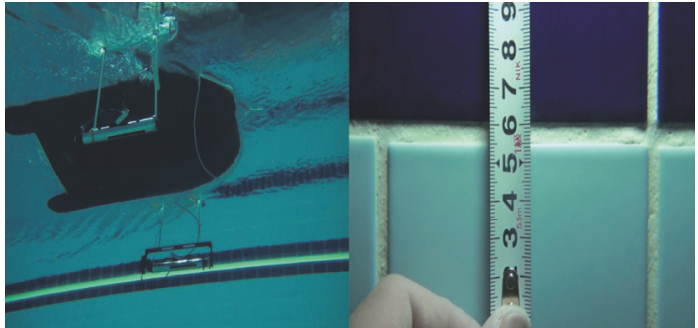

(a) Indoor test

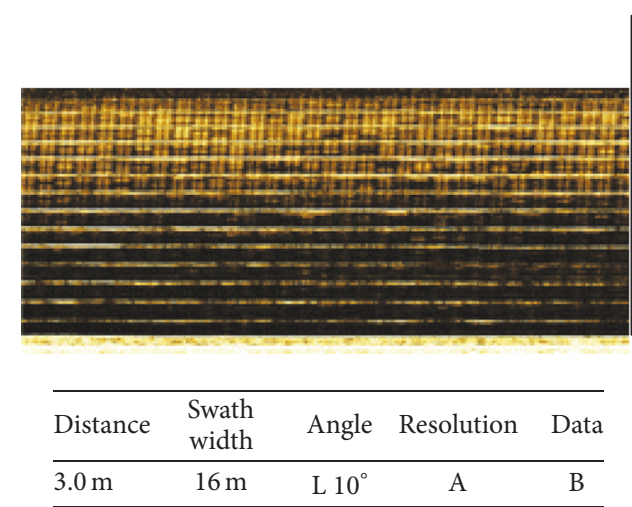

(c) Case 1 (distance $3 \mathrm{~m})$

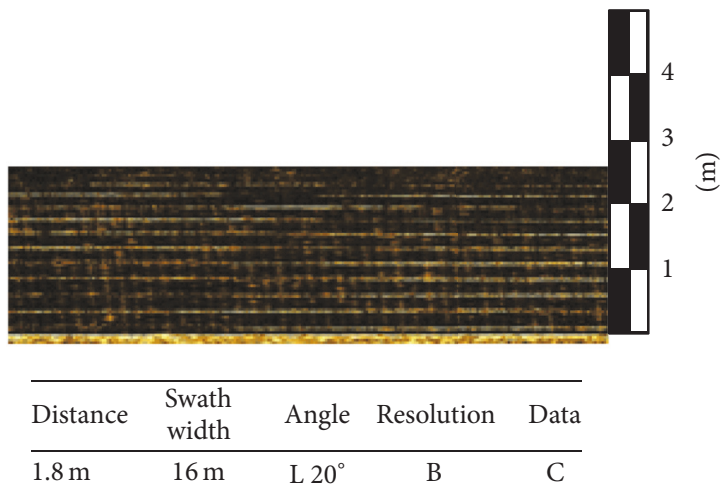

(e) Case $3\left(\right.$ degree L $\left.20^{\circ}\right)$

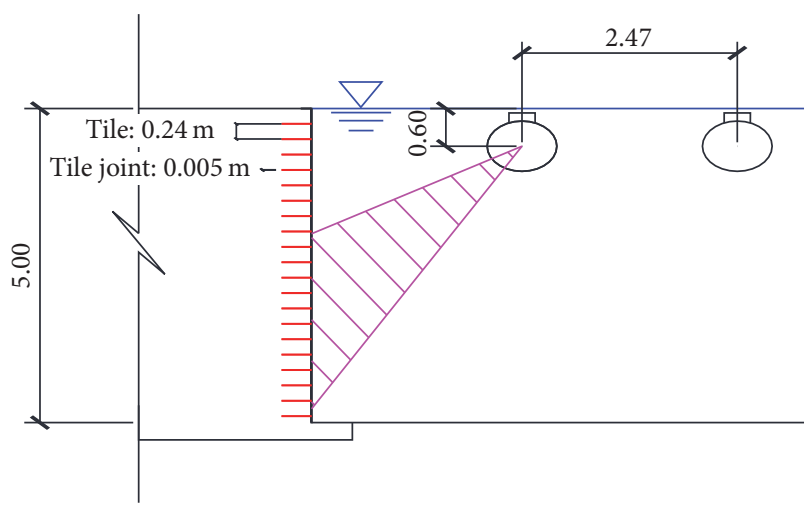

Beam area

(b) Concept of indoor test

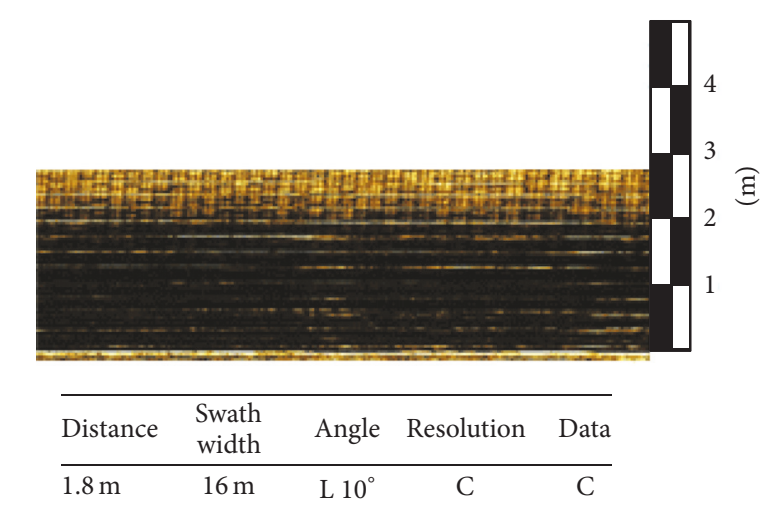

(d) Case 2 (distance)

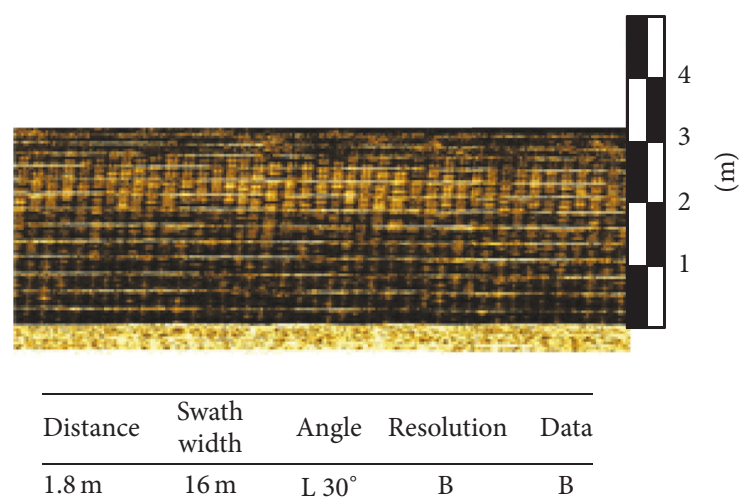

(f) Case $4\left(\right.$ degree L $\left.30^{\circ}\right)$

FIGURE 2: Indoor test and data.

structures, respectively. However, if two towfishes are operated, the overlapping of the sound waves occurs as shown in Figure 4, so that the interference of sound wave may occur. This was verified through laboratory experiments.

Figure 5 shows the overlapping area and nonoverlapping of sonar data. (a) in Figure 5 shows concept of indoor test and (b) is A grade of wall data to compare with overlapping area of sonar data. As shown in (c) and (d), the data of the overlapped part could not distinguish the indoor pool tile spacing due to sound wave interference, and the data quality was degraded.
If each control unit of two towfishes is used, sonar beam is not emitted at the same time. Therefore, when the radiated beam hits the surface of structure and reflects back, the interference of each signal occurs. And it was confirmed that the status cannot be surveyed by the acquired image.

As shown (a) in Figure 6, when sonar beam is emitted at different intervals, the interference of sound waves occurred with each other and sonar data quality is deteriorated. Therefore, it is designed to be able to radiate sonar beam at the same time as shown (b) in Figure 6. 
TABLE 2: Overlapping area occurs.

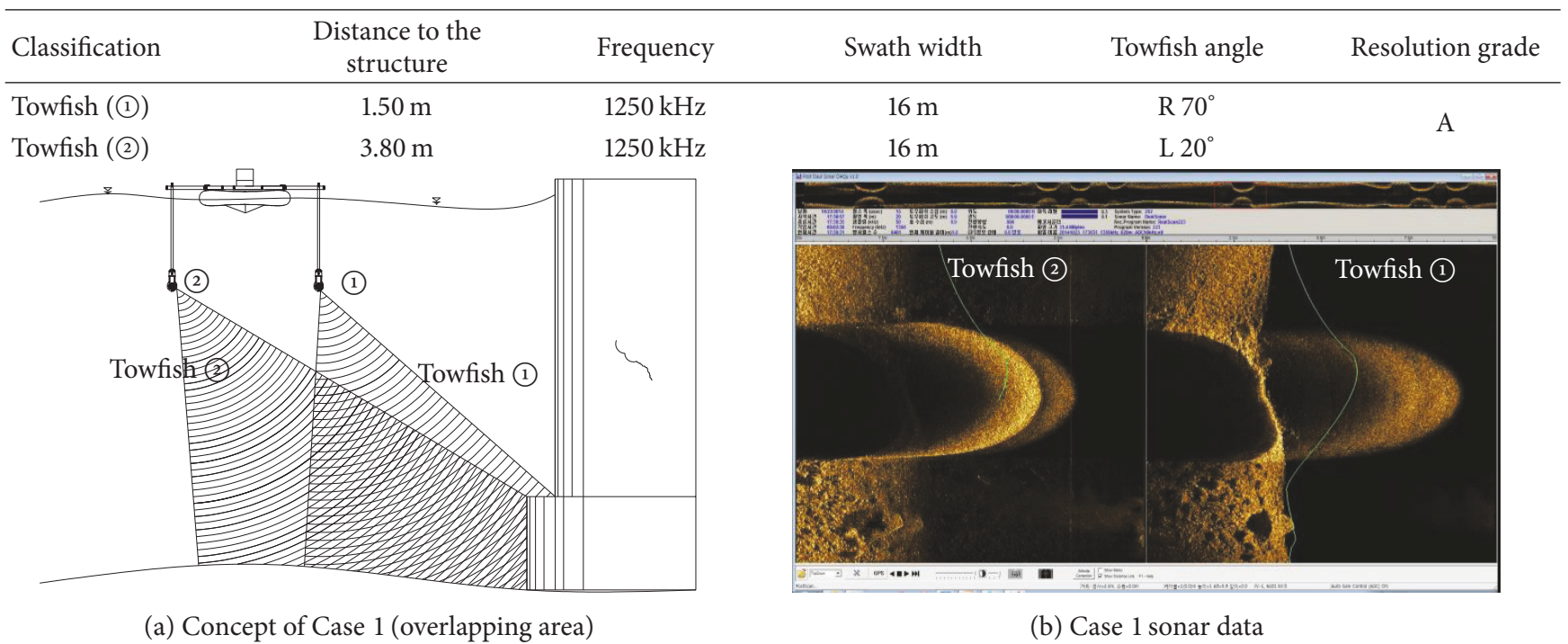

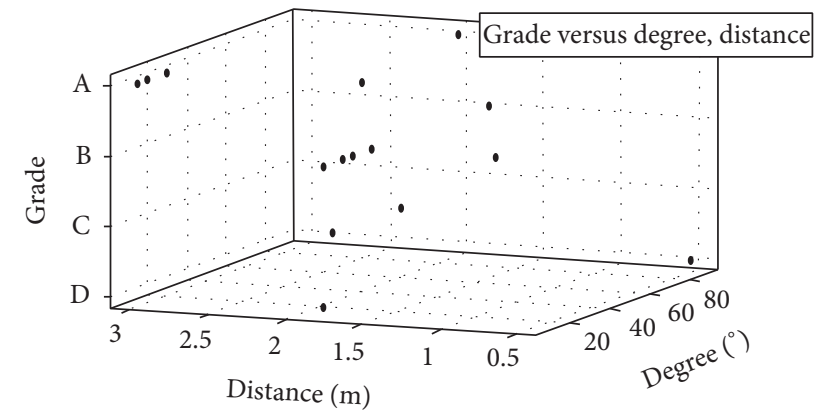

FIGURE 3: Change in resolution depending on distance and angle.

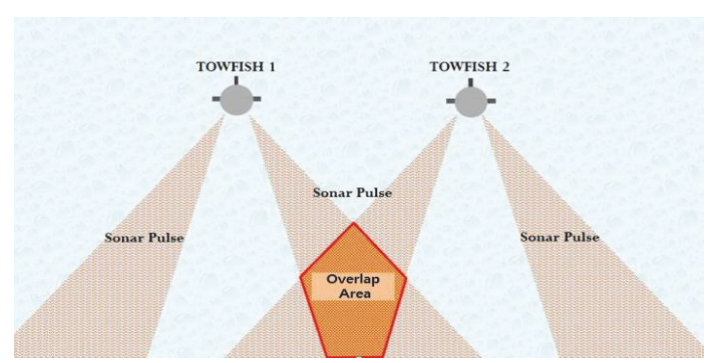

FIGURE 4: Occurrence of overlapped area due to acquisition of bidirectional underwater image.

In order to solve these problems, a controller and a dual sonar are developed as shown in Figure 6(c) so that sonar beams can be emitted simultaneously from two towfishes. The developed dual sonar is designed as shown in Figure 6(d) to control two towfishes simultaneously and to control sound wave irradiation interval of each towfishes. The beam is simultaneously radiated from the module of the transducer, thereby solving the problem that the interference of sound wave occurs.

\section{Field Application Analysis and Resolution Enhancement Technique}

3.1. Application of the Dual Sonar Sensor. In order to analyze the field applicability of the developed dual sonar, we measured the foundation and the lower surface of piers at towfish (right) and towfish (left) at the same frequency in the test-bed. Field test was performed with the existence of overlapping interval as a variable.

Table 2 shows the result of experiment in which overlapping sections are generated, and Table 3 shows experimental result in the case where there are no overlapping sections. The data of number 1 towfish and number 2 towfish in Table 2 show a resolution level despite the overlapping area. And there is no difference in resolution grade compared to the data in the case of no overlapping section.

As a result of comparing data that caused overlap and data that did not overlap, it was found that there was no difference in the quality and resolution of the data. So, it is considered that there is no influence of scattering and disturbance of sound waves in the overlapping section. The developed dual sonar can investigate underwater structures in addition to the surveying of river bed topography of the existing SSS. As underwater structures and river are simultaneously surveyed, the inspection period can be shortened and the inspection cost can be saved.

3.2. Resolution Enhancement by Multiple Regression Analysis. Through laboratory experiments, sonar data were confirmed to be influenced by distance from the structure and angle of the towfish. As the depth of field changes, angle of the towfish or distance is expected to change. In the field experiment, the prepared specimen was scanned while adjusting distance from the structure and angle of the towfish according to depth change. The specimen was scanned while adjusting the distance to the structure and angle of incidence according to the depth change. Optimal resolution was found to be $3 \mathrm{~cm}$ in 
TABLE 3: No overlapping area exists.

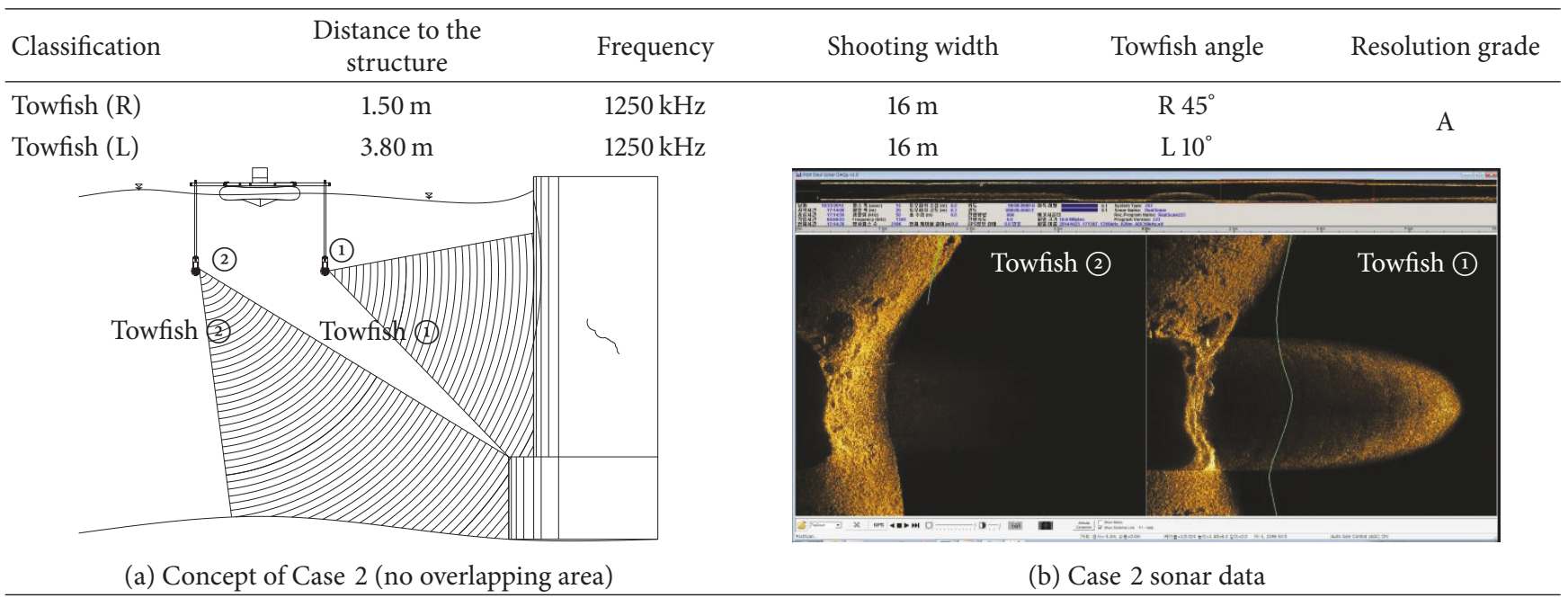

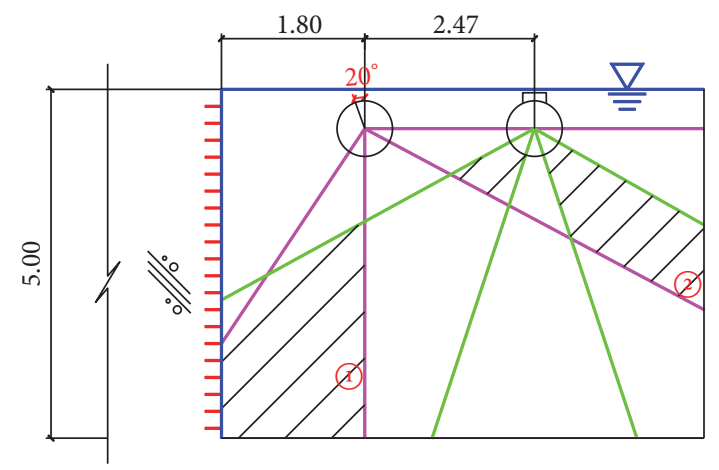

(a) Beam overlapped area

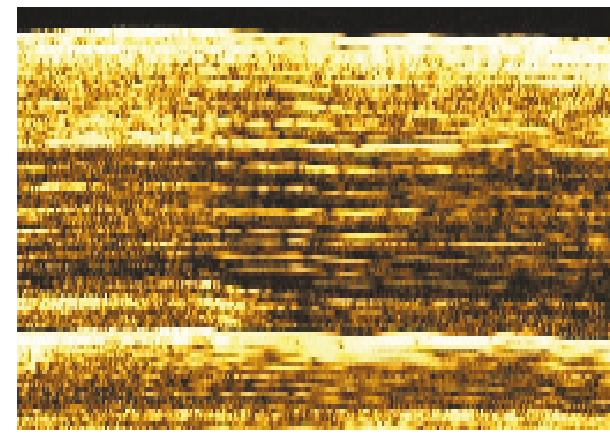

(c) Bed Overlap 1

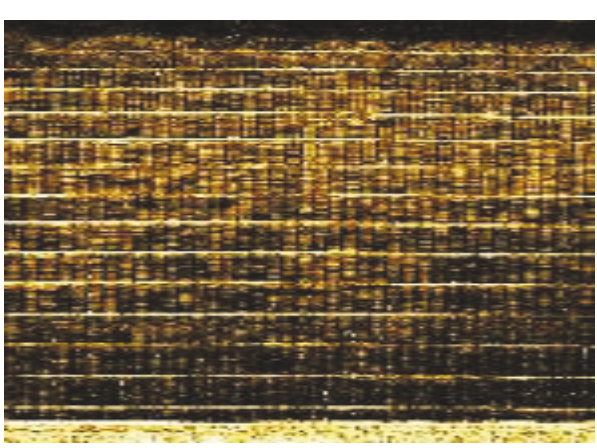

(b) Wall data

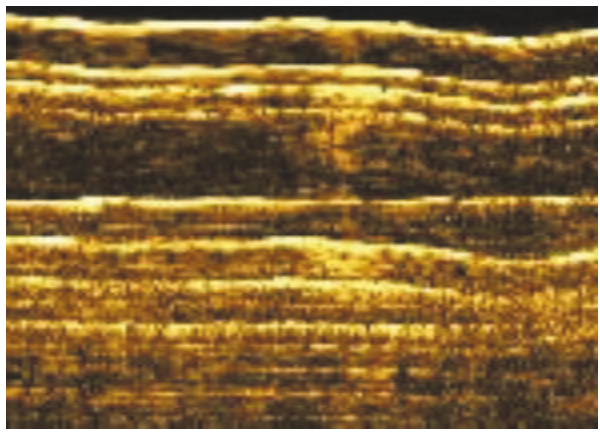

(d) Bed Overlap 2

FIGURE 5: Experimental diagram and data of interference according to frequency band.

specimen spacing, and 20 sample data items were extracted as shown in Figure 7. The white box in Figures 7(c) and 7(d) is the scanned image of specimen (b).

As shown in Table 4, when surveying underwater structures and riverbed, the left and right towfish are indicated as (1) + (3), and in the case of only surveying the riverbed, towfish is indicated by (2) + (3).

Multiple regression analysis is regression analysis where multiple independent variables are used to indicate changes in dependent variables when dependent variables are expected to be affected by two or more independent variables $[2,11]$. When the number of independent variables is $k$, the regression model is as follows:

$$
y_{i}=\beta_{0}+\beta_{1} x_{i 1}+\beta_{2} x_{i 2}+\cdots+\beta_{k} x_{i k}
$$

Here, $y$ is a dependent variable, $x_{1}, \ldots, x_{k}$ are the given independent variables, and $\beta_{1}, \ldots, \beta_{k}$ are the unknown regression coefficient. In this study, we have established a second-order or higher-order curve estimation model such 


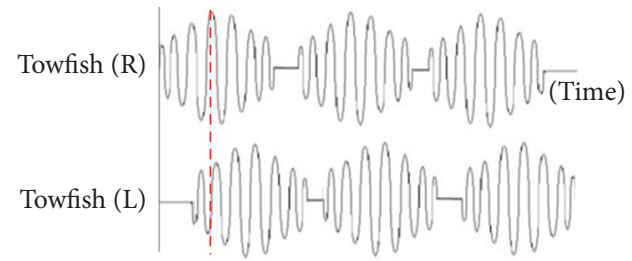

(a) Waveform using two towfishes

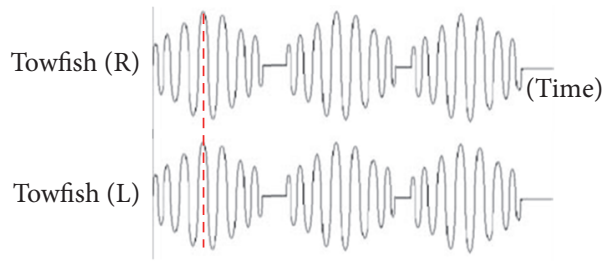

(b) Waveform of the dual sonar

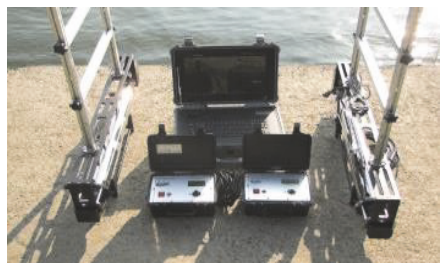

(c) Dual sonar sensor equipment

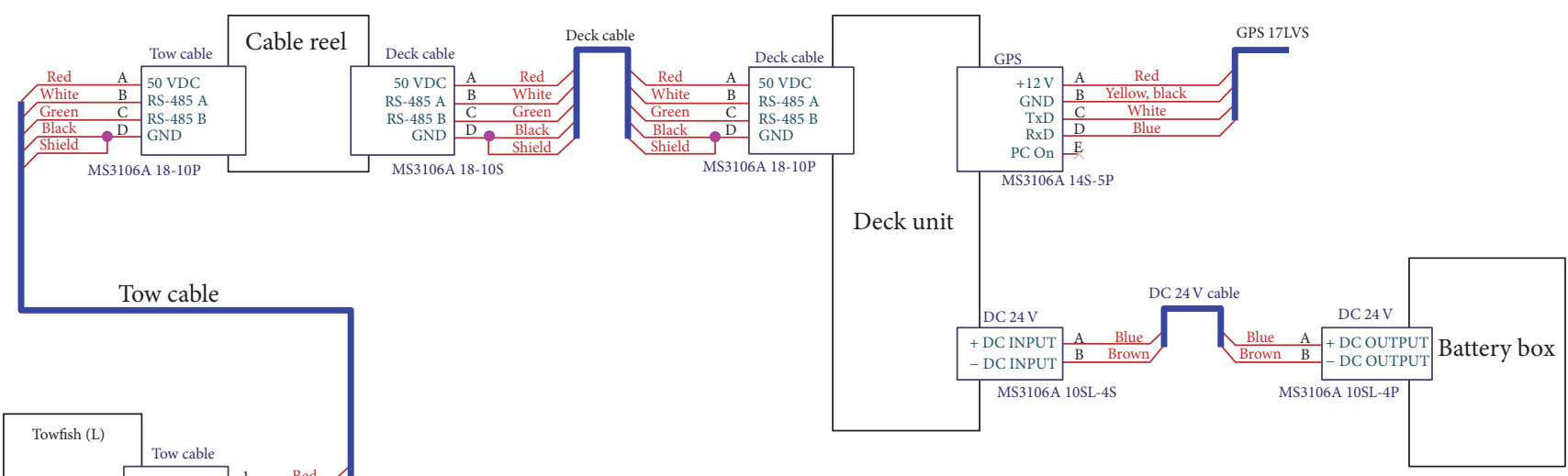

(d) Circuit diagram of dual sonar sensor

FIGURE 6: Graph of waveform and circuit diagram of the dual sonar.

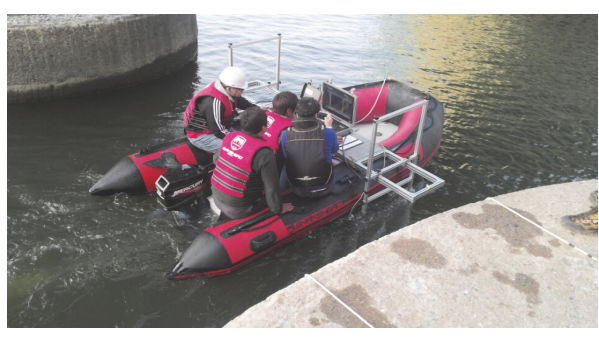

(a) Field experiment

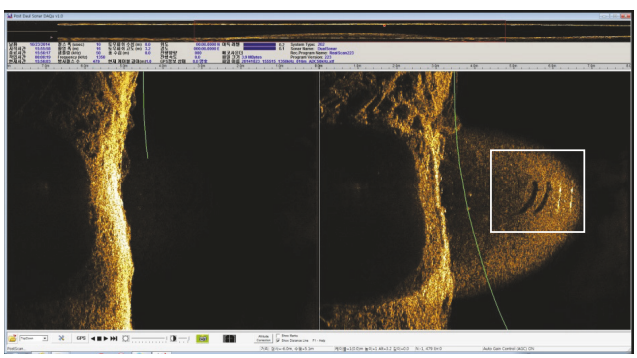

(c) Specimen of spacing $30 \mathrm{~cm}$

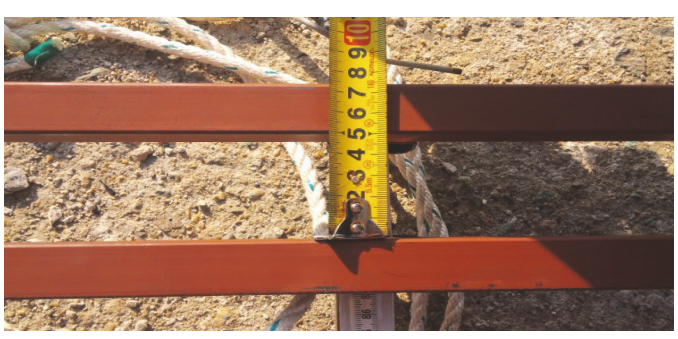

(b) Specimen

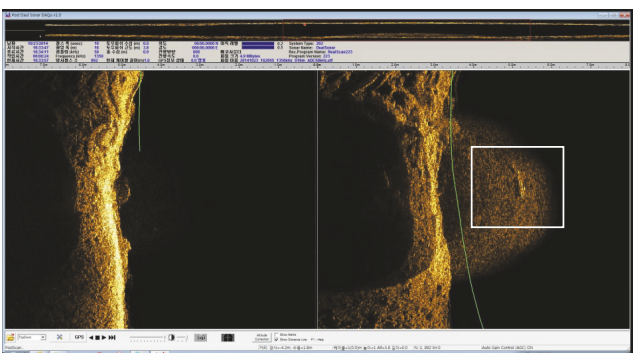

(d) Specimen of spacing $3 \mathrm{~cm}$

FIGURE 7: Field application experiment. 
TABLE 4: Sample data.

\begin{tabular}{|c|c|c|c|c|c|c|c|}
\hline \multirow{2}{*}{ Number } & \multirow{2}{*}{ Depth (m) } & \multicolumn{2}{|c|}{ (1) Towfish (L) (wall) } & \multicolumn{2}{|c|}{ (2) Towfish (L) (bed) } & \multicolumn{2}{|c|}{ (3) Towfish (R) (bed) } \\
\hline & & Angle (R) & Distance $(\mathrm{m})$ & Angle (R) & Distance $(\mathrm{m})$ & Angle (R) & Distance $(\mathrm{m})$ \\
\hline 1 & 4.6 & 53.6 & 1.6 & -2.7 & 14.0 & 140.0 & 3.9 \\
\hline 2 & 3.8 & 51.2 & 1.5 & -2.4 & 13.6 & 141.0 & 3.8 \\
\hline 3 & 3.1 & 50.6 & 1.4 & -2.1 & 13.3 & 143.0 & 3.7 \\
\hline 4 & 9.1 & 51.3 & 1.6 & -3.1 & 16.1 & 137.0 & 3.9 \\
\hline$\vdots$ & $\vdots$ & $\vdots$ & $\vdots$ & $\vdots$ & $\vdots$ & $\vdots$ & $\vdots$ \\
\hline 15 & 7.3 & 50.4 & 1.3 & -3.0 & 15.2 & 138.5 & 3.6 \\
\hline 16 & 3.9 & 51.5 & 1.2 & -3.1 & 13.6 & 139.9 & 3.5 \\
\hline 17 & 4.8 & 51.2 & 1.2 & -2.7 & 14.0 & 139.5 & 3.5 \\
\hline 20 & 8.2 & 50.2 & 1.4 & -3.0 & 15.7 & 138.1 & 3.7 \\
\hline
\end{tabular}

as since the relationship between angle of the towfish (dependent variable) and two independent variable distributions is more than quadratic.

$$
\begin{aligned}
f(x, y)= & \beta_{00}+\beta_{10} x+\beta_{01} y+\beta_{20} x^{2}+\beta_{11} x y \\
& +\beta_{02} y^{2} .
\end{aligned}
$$

The basis of multiple regression analysis is the method of least residual squares. To minimize this error, the function is differentiated for each unknown. This is a method of going back to a value whose differential value becomes zero [12]. The coefficient of correlation used in this study is coefficient of determination and adjusted $R$-square, and the coefficient of determination can be expressed as the square of the correlation coefficient $R$ [13]. In addition, to prevent the correlation $R_{\text {adj }}^{2}$ from increasing because of the addition of a relatively low independent variable, the coefficient of determination after adjustment was used [14]. This is shown in the following:

$$
R_{\mathrm{adj}}^{2}=1-\frac{\left(1-R^{2}\right)(n-1)}{n-k-1} .
$$

To verify the reliability of the derived multilinear regression equation, correlation coefficient, decision coefficient, correction coefficient, and error were calculated. The error was calculated using RMSE (Root Mean Square Error), and the error is shown in the following:

$$
\mathrm{RMSE}=\sqrt{\frac{1}{N} \sum_{i=1}^{n}\left(M_{n}-P_{n}\right)^{2}} .
$$

The Matlab 2016b program was used to analyze the correlation between depth of the water and angle of the towfish, and the multiple regression model for the final towfish survey is shown in the following (5) to (7). From (2), dependent variables $x, y$ and regression coefficients $\beta_{00}, \ldots, \beta_{02}$ were obtained as follows.

$$
\begin{aligned}
Y_{\text {LS }}= & 100.3+1.953 x-81.38 y-0.0128 x^{2}-1.396 x y \\
& +32.98 y^{2}
\end{aligned}
$$

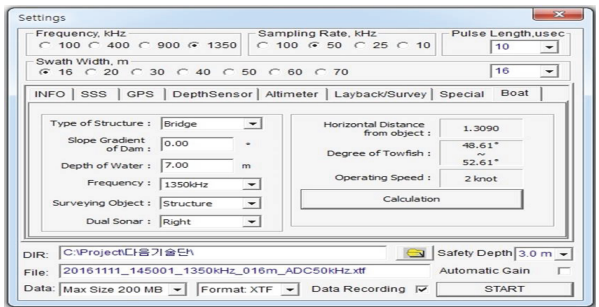

FIgURE 8: Dual sonar sensor operating program tool.

$$
\begin{aligned}
Y_{\mathrm{LB}}= & 941.2+90.93 x-168.8 y+2.151 x^{2}-8.089 x y \\
& +7.537 y^{2} \\
Y_{\mathrm{RB}}= & 131.9+3.919 x-1.87 y+0.06189 x^{2}-1.421 x y \\
& +1.453 y^{2}
\end{aligned}
$$

where $x$ is depth of water, $y$ is distance from the structure, $Y_{\text {LS }}$ is angle of the towfish (left) when surveying the underwater structure, $Y_{\mathrm{LB}}$ is angle of the towfish (left), and $Y_{\mathrm{RB}}$ is angle of the towfish (right) when surveying the bed. The regression model graphs and decision coefficients are summarized in Table 5.

$R^{2}$ ( $R$-square), which is the adjusted coefficient of determination, is $0.65 \sim 0.93$, and the effect of distance between water depth and structure on angle of the towfish is 65 93\%. As shown in Table 6, the significance of the proposed regression coefficients was obtained by $t$-test [15]. As a result of analysis, the distance between water depth and structure showed a major influence on angle of the towfish. In this case, since the $P$ value, which is probability of significance, indicates the degree of rejection of the null hypothesis that the independent variable affects the dependent variable, it can be judged that the smaller the $P$ value is, the more significant it is $[14,16]$. The larger value and the more independent variables affect the dependent variable because the standardization factor $(\beta)$ is an indicator of the influence of each independent variable on the dependent variable [17].

The RealDualSONAR-DAQ such as that in Figure 8, a program for the operation of distance between water depth 
TABLE 5: Multiple regression analysis results.

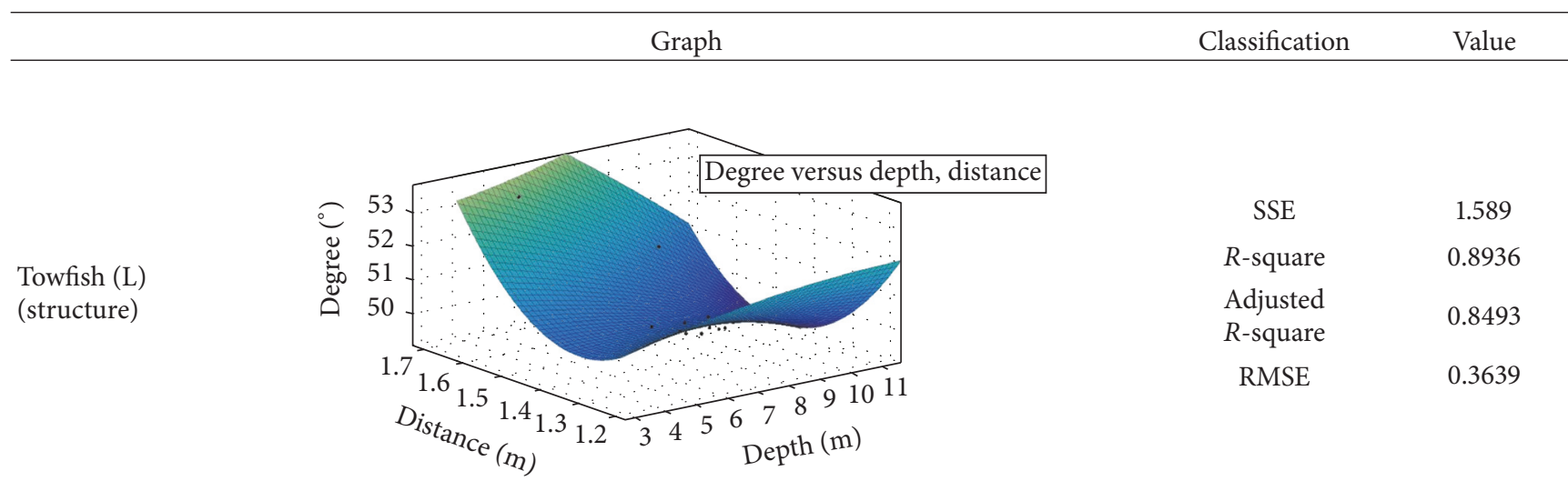

Towfish

(L) (bed)

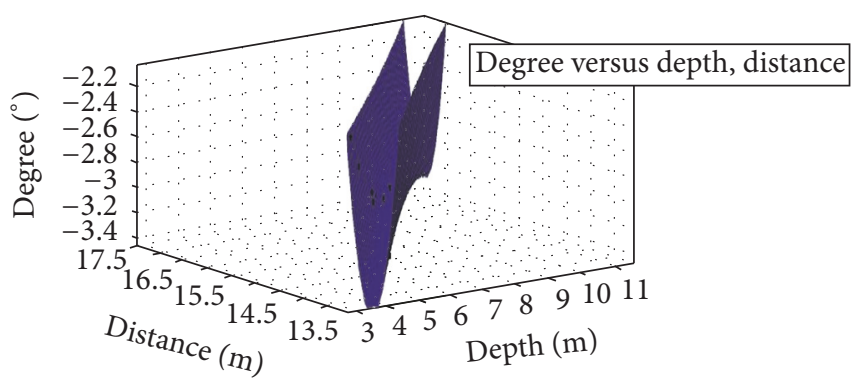

$\begin{array}{cc}\text { SSE } & 0.3823 \\ R \text {-square } & 0.7546 \\ \begin{array}{c}\text { Adjusted } \\ R \text {-square }\end{array} & 0.6523 \\ \text { RMSE } & 0.1785\end{array}$

Towfish

(R) (bed)

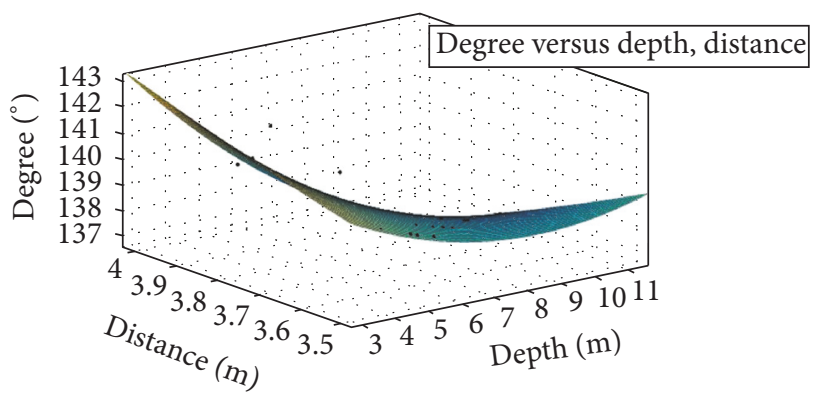

$\begin{array}{cc}\text { SSE } & 1.771 \\ R \text {-square } & 0.951 \\ \begin{array}{c}\text { Adjusted } \\ R \text {-square }\end{array} & 0.9306 \\ \text { RMSE } & 0.384\end{array}$

TABLE 6: Coefficient of effective factors.

\begin{tabular}{|c|c|c|c|c|c|}
\hline & Effective factors & $B$ & $\beta$ & $t$ & $P$ \\
\hline \multirow{2}{*}{ Towfish (L) (structure) } & Depth & -0.308 & -0.740 & -3.966 & 0.001 \\
\hline & Distance & 3.708 & 0.600 & 3.215 & 0.006 \\
\hline \multirow{2}{*}{ Towfish (L) (bed) } & Depth & -1.089 & -8.099 & -2.706 & 0.016 \\
\hline & Distance & 2.042 & 7.390 & 2.469 & 0.026 \\
\hline \multirow{2}{*}{ Towfish (R) (bed) } & Depth & -0.637 & -0.983 & -9.245 & 0.000 \\
\hline & Distance & 1.801 & 0.187 & 1.762 & 0.098 \\
\hline
\end{tabular}


and structure and angle of the towfish, was developed based on the equation derived by the above regression analysis and provides operational information of sonar by linking sonar survey distance and angle. The high resolution data can be obtained by entering type and depth of structure in the setting window before the dual sonar operation.

\section{Conclusion}

In this study, we developed the equipment to investigate damage of underwater structures effectively using the dual sonar and studied the operation method to improve the resolution of sonar data. Through the indoor experiment, we confirmed sound wave interference phenomenon in the overlapping section of the dual sonar operation and verified that sonar data resolution depends on the distance between water depth and structure and angle of towfish. In the dual sonar operation, the problem of sound wave interference phenomenon which occurred in the overlapped region was solved by the control part design and module development, and it was verified through the field experiment.

In addition, it was found that the optimal resolution was obtained when the interval of $3 \mathrm{~cm}$ specimens could be identified through the test, and 20 sample data items for each survey item were extracted. The regression model for the object of investigation was derived through multiple regression analysis. The derived regression model explains that the influence of distance between water depth and structure on angle of the towfish angle is 65 93\%. The significance test was confirmed by $t$-test, and distance between water depth and structure was found to have a major influence on the survey angle. The RealDualSONAR-DAQ, the dual sonar operating program, was developed based on the derived correlation. Since this is based on empirical data of the dual sonar of $1 \mathrm{MHz}$, it is necessary to verify and update the derived model through a lot of data accumulation in the future.

Through this study, it is possible to obtain the appropriate survey angle of towfish by using data of depth and distance collected from the field. Therefore, it is possible to prevent degradation of sonar data due to inexperienced operations and to obtain good sonar data to analyze damage of underwater structure. Based on the accurate sonar data, which is the result of this study, it is considered that reliable safety evaluation of underwater structures is possible.

\section{Conflicts of Interest}

The authors declare no conflicts of interest regarding the publication of this paper.

\section{Acknowledgments}

This paper is a study conducted with the support of the Korea Agency for Infrastructure Technology Advancement funded by the government (Ministry of Land, Infrastructure and Transport) in 2016 (no. 16CTAP-C097867-02).

\section{References}

[1] Central Disaster and Safety Countermeasure Headquarter, Disaster Annals, 2012 (Korean).

[2] H.-S. A. Alfredo and W. H. Tang, Probability Concepts in Engineering: Empahsis on Applications in Civil \& Environmental engineering, John Wiley \& Sons, 2007.

[3] D. Agdas, J. A. Rice, J. R. Martinez, and I. R. Lasa, "Comparison of visual inspection and structural-health monitoring as bridge condition assessment methods," Journal of Performance of Constructed Facilities, vol. 30, no. 3, 2016.

[4] J.-H. Park, Y.-S. Park, C. Park, and J.-J. Lee, "Development of sonar sensor-based smart underwater inspection system," in Proceedings of the Korea Institute for Structural Maintenance and Inspection Conference, vol. 17, pp. 126-129, 2013.

[5] V. Chandran, S. Elgar, and A. Nguyen, "Detection of mines in acoustic images using higher order spectral features," IEEE Journal of Oceanic Engineering, vol. 27, no. 3, pp. 610-618, 2002.

[6] C. Park, A study on the development of safety inspection method in underwater structures using a high resolution SONAR sensor [Ph.D. thesis], Hanyang University, 2015.

[7] Y. Kim, C. Park, and S. Choi, "A study of operation methods for application of safety inspection of underwater structures using high resolution side scan SONAR sensor," Korea Society of Coastal Disaster Prevention, vol. 3, no. 2, pp. 67-73, 2016.

[8] C. Park, Y. Kim, and S. Choi, "A regression analysis study of the applicability of side scan SONAR sensor based safety inspection of underwater structures," in Proceedings of the 18th International Conference on Nondestructive Testing and Evaluation, 2016.

[9] F. Ollivier, P. Cervenka, and P. Alais, "Side scan SONAR using phased arrays for high resolution imaging and wide swath bathymetry," The Institution of Electrical Engineers, vol. 143, no. 3, pp. 163-168, 1996.

[10] H.-N. Ho, J.-J. Lee, C. Park, and B.-W. Jo, "An efficient image enhancement algorithm for sonar sensor data," International Journal of Latest Research in Science and Technology, vol. 2, no. 6, pp. 38-43, 2013.

[11] C. Petroutsatou, S. Lambropoulos, and J. Pantouvakis, "Road tunnel early cost estimates using multiple regression analysis," Operational Research, vol. 6, no. 3, pp. 311-322, 2006.

[12] A. Sorsa, A. Isokangas, S. Santa-Aho, M. Vippola, T. Lepistö, and K. Leiviskä, "Prediction of residual stresses using partial least squares regression on barkhausen noise signals," Journal of Nondestructive Evaluation, vol. 33, no. 1, pp. 43-50, 2014.

[13] M. Kumar and V. K. Srivastava, "Pitman nearness and concentration probability comparisons of the sample coefficient of determination and its adjusted version in linear regression models," Communications in Statistics. Theory and Methods, vol. 33, no. 7, pp. 1629-1641, 2004.

[14] S. Lee, D. Kim, and Y. Choi, "Development of predictive model for the number of potholes using multi regression analysis," Journal of Korean Society of Hazard Mitigation, vol. 14, no. 3, pp. 91-98, 2014.

[15] K. Cha, S. Kim, J. H. Kim, M. Park, and J. S. Kong, "Development of the deterioration models for the port structures by the multiple regression analysis and markov chain," Journal of the Computational Structural Engineering Institute of Korea, vol. 28, no. 3, pp. 229-239, 2015. 
[16] S. C. Chelgani, B. Hart, W. C. Grady, and J. C. Hower, "Study relationship between inorganic and organic coal analysis with gross calorific value by multiple regression and ANFIS," International Journal of Coal Preparation and Utilization, vol. 31, no. 1, pp. 9-19, 2011.

[17] V. Mokhtari, "Regression analysis of factors in the agricultural production cooperative success of Ilam," Journal of Trends in Advanced Science and Engineering, vol. 4, no. 2, pp. 100-109, 2012. 


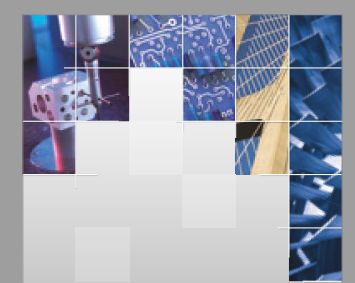

\section{Enfincering}
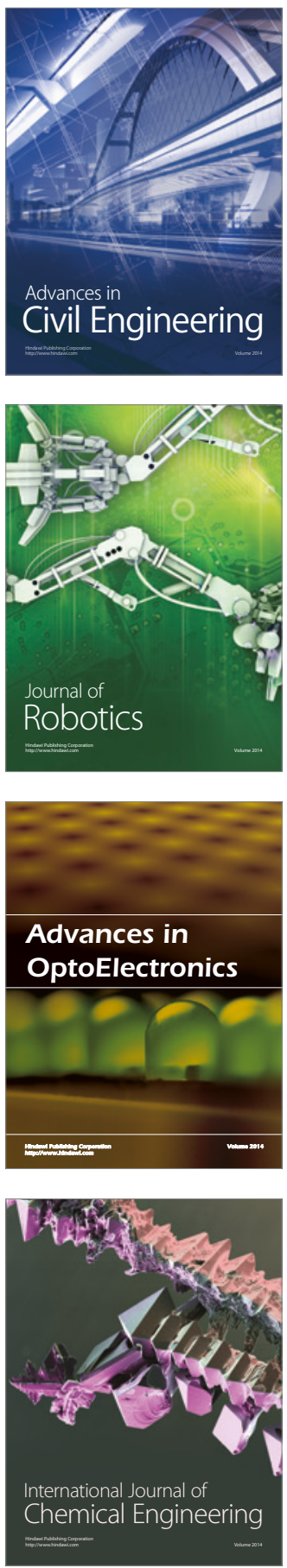

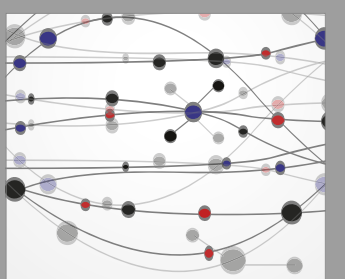

The Scientific World Journal

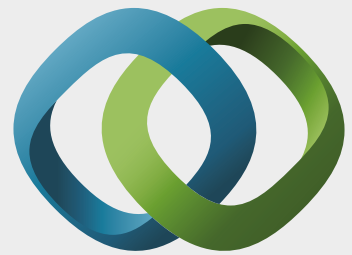

\section{Hindawi}

Submit your manuscripts at

https://www.hindawi.com
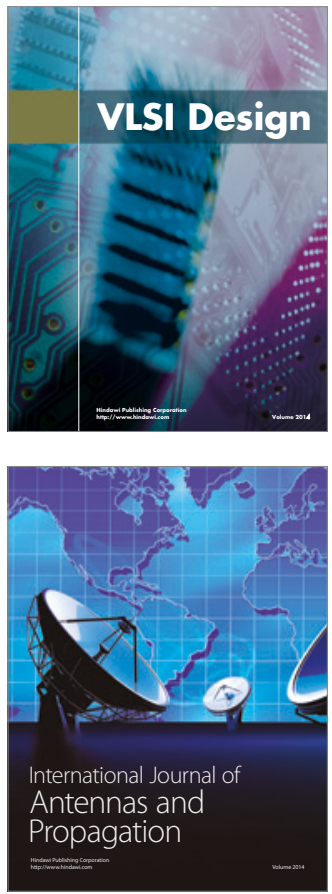

\section{Rotating}

Machinery
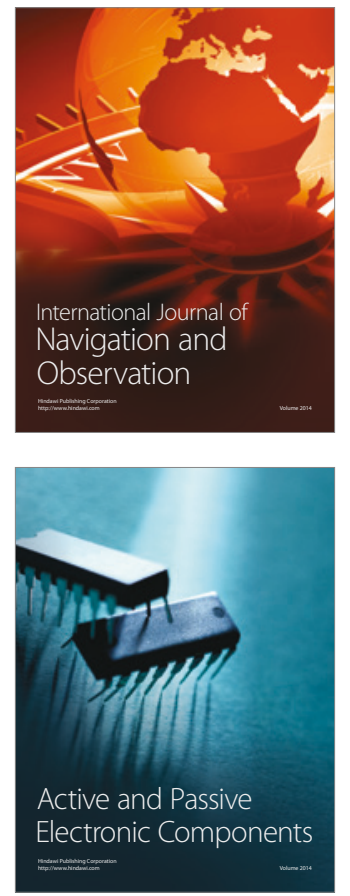
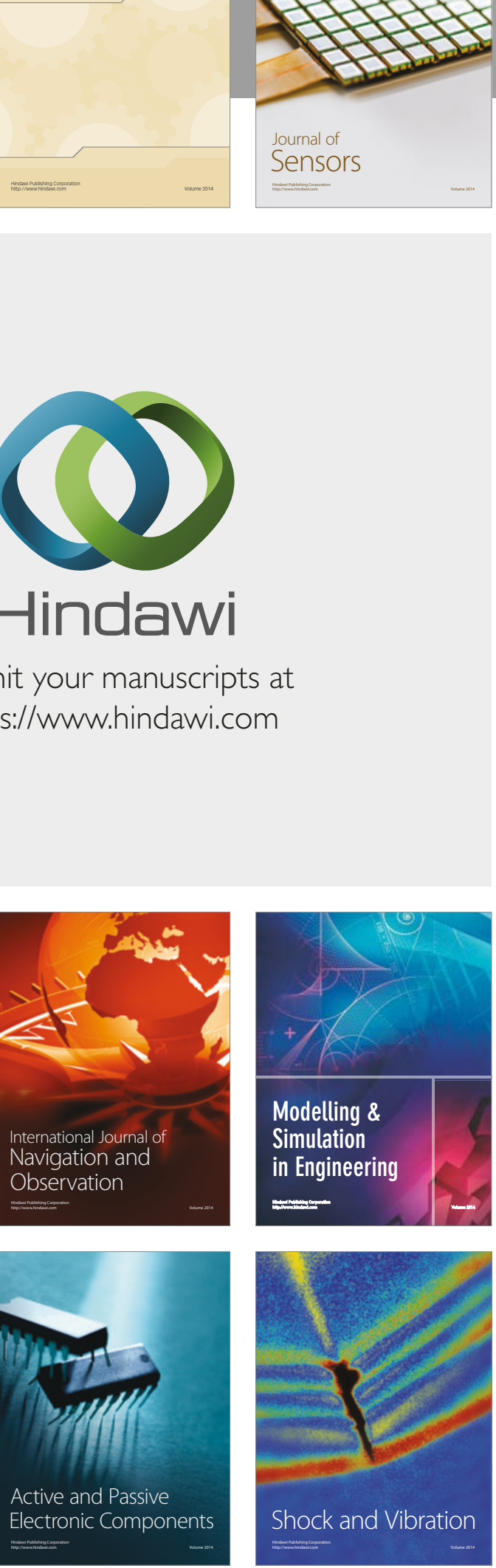
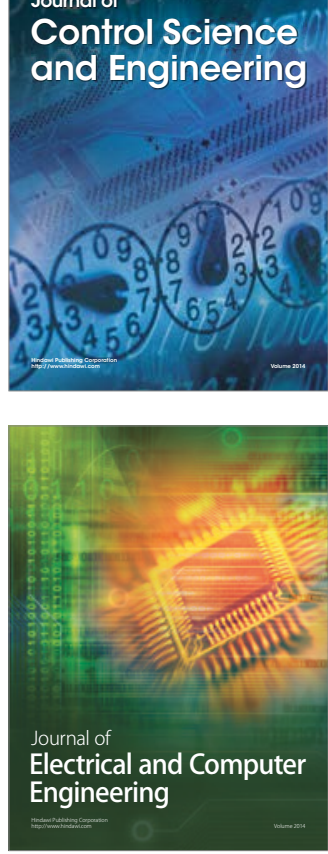

Distributed

Journal of

Control Science

and Engineering
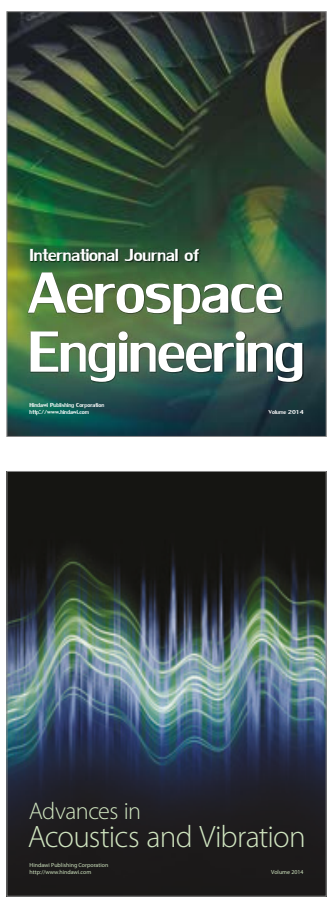

Sensor Networks 